\title{
METÁFORAS E DEPENDÊNCIA QUÍMICA
}

\author{
METAPHORS AND CHEMICAL DEPENDENCE
}

\author{
José BAUS ${ }^{1}$ \\ Ana Carolina SEARA \\ Carla Maria Wojcikiewicz CALDAS \\ Luana DESIDÉRIO \\ Nivaldo PETRY FILHO
}

\begin{abstract}
RESUMO
Metáforas estão presentes no discurso de dependentes químicos participantes de grupos de ajuda mútua. Neste estudo, procurou-se identificar, através da análise do conteúdo do discurso de quatro participantes de um grupo de ajuda mútua de dependentes químicos, as metáforas relativas à dependência química e aos processos de recaída e de recuperação e suas relações com a teoria, implícita ou explícita, sobre dependência química, adotada por esses participantes. As entrevistas foram semi-estruturadas, gravadas e transcritas. Os resultados indicaram a presença de sete metáforas: duas acerca do processo de recaída, uma relativa ao processo de recuperação, duas acerca da dependência química e duas a respeito do grupo de ajuda mútua. Evidenciou-se uma congruência entre essas metáforas e o modelo de dependência química como doença crônica, nos moldes tradicionais do Alcoólicos Anônimos.
\end{abstract}

Palavras-chave: metáfora, dependência química, recaída, recuperação.

\section{ABSTRACT}

Metaphors are present in the discourse of chemical dependents who participate in self-help groups. In this study, the analysis of discourse of

\footnotetext{
(1) José Baus, Doutor em Psicologia Experimental, Professor Adjunto do Departamento de Psicologia, Centro de Filosofia e Ciências Humanas, Universidade Federal de Santa Catarina, Campus Universitário, Caixa Postal 476 - CEP 88010-970 Florianópolis, SC - Fone: (0*48) 331-9283 Fone-fax: (0*48) 331-9984 - e-mail: baus@cfh.ufsc.br. Os demais autores são alunos de graduação do Curso de Psicologia da UFSC.

Os autores agradecem a colaboração dos quatro participantes do grupo de ajuda mútua que, com a maior disponibilidade, contribuíram para a realização desta pesquisa; ao Prof. Dr. Rogério Ferreira Guerra, do Departamento de Psicologia da UFSC, pelos comentários e sugestões valiosas para o aperfeiçoamento deste texto.
} 


\begin{abstract}
four members of one self-help group of chemical dependents was used to identify different metaphors related to chemical dependence and the processes of relapse and recovering, as well as their implicit or explicit relationship with participants' folk theories of chemical dependence. Semi-structured interviews were taped and transcribed. The results showed seven metaphors: two about the relapse process, one about the recovering process, two about chemical dependence and two about the self-help group. Evidence was found about the congruence between these metaphors and the chemical dependence model emphasizing the chronic disease aspect, well in line with the tradition of Alcoholics Anonymous.
\end{abstract}

Keywords: metaphor, chemical dependence, relapse, recovering.

Metáforas estão presentes na linguagem cotidiana e, de acordo com Vosniadou e Ortony (1989), são analogias que nos permitem mapear uma experiência através da terminologia de uma outra experiência, contribuindo para a compreensão de tópicos complexos ou novas situações.

Cinco razões levam Moser (2000) a propor a análise da metáfora como um instrumento valioso na pesquisa psicológica: 1) elas influenciam o processamento da informação, nos processos de auto-reflexão, antecipação de ações e comunicação interpessoal; 2) são uma operacionalização confiável e acessível do conhecimento tácito; 3) são representações holísticas de compreensão e conhecimento; 4) as metáforas convencionais são exemplos de ação automatizada e, de sua análise, podese identificar uma determinada teoria implícita; e, por último, elas refletem processos de compreensão social e cultural.

Nos grupos de ajuda mútua, cujos participantes apresentam uma história de dependência química, é bastante freqüente ouvirem-se depoimentos de seus membros em que determinadas metáforas são utilizadas para descrever os processos de recuperação e de recaída, o significado da dependência como doença, e assim por diante. Em estudo anterior, Pick e Baus (1996), através da análise de verbalizações de dependentes químicos, emitidas em reuniões de um determinado grupo de ajuda, observaram o uso freqüente das seguintes metáforas: escalar uma cachoeira, carregar um fardo, reacender uma vela e estar com o pé na lama. As duas primeiras (cachoeira e fardo) destacam a necessidade da persistência diante dos obstáculos, o custo da resposta envolvido no processo de mudança de comportamento e de atitude frente à droga. A terceira (reacender a vela) se relaciona-se com uma concepção de dependência química como doença crônica e progressiva, ao enfatizar que, com o primeiro gole, reativa-se o processo de perda de controle: reacende-se a chama, finalmente, a metáfora do "pé-na-lama" faz referência a outras analogias: "lixo humano" e "vegetal", associadas aos significados de perda da dignidade e da liberdade humanas a que a recaída pode conduzir.

Como se verificou acima, as metáforas desempenham funções relevantes tanto nos processos intrapessoais como interpessoais. Dentre as contribuições que o estudo das metáforas pode trazer para a pesquisa psicológica, Moser (2000) incluiu aquela de permitir acesso à estrutura e conteúdo das teorias implícitas subjacentes ao seu emprego automatizado. Por outro lado, é possível, também, que metáforas apareçam inseridas no discurso do dependente químico quando este inclui passagens que deixam explícita a teoria sobre a dependência química professada por ele ou, pelo menos, que é hegemônica no seu grupo de ajuda mútua. 
Este estudo procurou fazer um levantamento das metáforas relativas à dependência química, presentes no discurso de participantes de um grupo de ajuda mútua, quando lhes é solicitado discorrer sobre o processo de recaída e de que forma estariam relacionadas com sua teoria a respeito do que é dependência química e o processo de recuperação do dependente químico.

\section{MÉTODO}

Participantes: quatro dependentes químicos em processo de recuperação junto a um grupo de ajuda mútua há, pelo menos, cinco anos. Os quatro são do sexo masculino: um com 24 anos de idade, outro com 42, o terceiro com 45 e o quarto com 50 .

Procedimento de coleta de dados: entrevista semi-estruturada. Iniciava-se com uma pergunta "O que é recaída, para ti?". O entrevistador centralizava-se em questões que permitissem obter informações sobre o conceito de recaída, as condições que facilitam ou dificultam a recaída, exemplos do cotidiano do dependente. As entrevistas eram gravadas (gravador de som) mediante consentimento expresso do participante. Transcritas, eram submetidas à análise de conteúdo, registrandose, numa matriz, numa coluna ao lado do texto transcrito, as sínteses temáticas com respectivos excertos da fala do entrevistado.

Utilizou-se para dois dos participantes (C e D) a técnica da recorrência, ou seja, após a análise de conteúdo dos dados obtidos na primeira sessão, retornava-se à segunda sessão, com o participante, visando ampliar ou retificar suas informações e pontos devista.

Procedimentos de análise de dados: análise de conteúdo.

\section{RESULTADOS}

Apresenta-se, em relação a cada um dos quatro participantes, uma síntese, através da qual se procura identificar as metáforas empregadas e suas possíveis relações com definições do processo de recaída e sua concepção a respeito da dependência química. Finalmente, faz-se uma análise global dessas quatro sínteses.

\section{1) Participante $A$}

Este participante estabelece uma diferença entre resvalo (deslize ou escorregão) e recaída. O resvalo consiste numa perda momentânea do autocontrole sobre o uso da droga que pode levar o indivíduo à recaída, um estado mais prolongado do abuso de droga e que se caracteriza pela chegada ao "fundo do poço": "(...) a pessoa faz uso da droga e não consegue mais sair de onde está, do estado que estava (...)". Três analogias foram usadas para caracterizar a situação com a qual o dependente químico passa a conviver: desveste-se de sua humanidade ("vira um vegetal"), passa a conviver com a impureza ("um lixo humano, ... é quando vai para a lama").

Para este participante, a compreensão acerca de determinado processo de recaída pressupõe um conhecimento da história do dependente químico em relação ao uso indevido de droga ("para entender o que foi essa minha recaída, teria de entender a minha vida lá atrás ..."): onde encontrar seus colegas da "ativa" (abusadores ou fornecedores de droga), seu estado emocional propício ao consumo de droga (frustração ou raiva intensa).

\section{2) Participante $B$}

A recaída é vista como uma manifestação (sintoma) de uma doença crônica (a dependência química), da qual o indivíduo é portador. Mantendo-se abstinente, o dependente consegue apenas silenciar momentaneamente a sua doença. O principal fator relacionado com o aparecimento desse sintoma seria a desatenção ou negligência em 
desenvolver as habilidades necessárias de enfrentamento diante das insinuações da droga, ou seja, ceder à tentação do "primeiro gole"...

Supõe-se que a convicção manifesta por este participante a respeito do seu envolvimento consciente no último processo de recaída se deva a seu conhecimento relativamente profundo acerca da dependência química e do processo de recuperação, dentro de um modelo de doença crônica (progressiva, incurável e fatal), associado à sua história vasta e diferenciada em termos de tratamento e de recaídas. Daí decorreria a auto-imputação de sua responsabilidade pela última recaída. Acredita-se também que, de uma maior clareza sobre essa "doença" e sobre o processo de recaída, deva-se deduzir uma maior consciência (clareza?) diante desse processo, daí surgindo o sentimento exacerbado de culpa diante de seu fracasso em autocontrolar-se naquela situação. Em outras palavras: o dependente químico somente deveria ser responsabilizado moralmente por seu comportamento de abuso de drogas a partir do momento em que, tendo adquirido clareza a respeito da sua doença, cede à tentação do primeiro gole. Daí a necessidade de auto monitoramento constante a que se fez referência no primeiro parágrafo. Caso contrário, ou seja, ceder à tentação do primeiro gole poderá conduzi-lo novamente ao "fundo do poço", uma situação de desamparo e abandono. É portanto, a partir da consciência de que é portador de uma doença e de que todo o cuidado é pouco para evitar que ela se reinstale após o primeiro gole, que se deve entender como se coloca, para este dependente químico, a questão da responsabilidade moral, em relação ao uso indevido de drogas. Se, por um lado, a noção de doença parece eximi-lo da responsabilidade pelos equívocos cometidos em seu passado em decorrência do uso indevido da droga, por outro lado, não há como eximir-se de tal responsabilidade, após ter adquirido consciência de que convive com uma doença e acerca dos cuidados para evitar o seu recrudescimento.
Duas metáforas parecem estar associadas a essa maneira de compreender a dependência química como doença e o processo de recuperação: a droga como agente/objeto de sedução e a recuperação como trilhar por um caminho estreito à margem de precipícios. Observe-se a linguagem com que este participante expressa sua maneira de encarar a recaída através da metáfora da droga como agente/objeto sedutor: “ (...) Ela vem de várias maneiras. Ela é sutil, suave, e quando tu deparas prá ti, tu já tá fazendo ... E' incrível! (...)". É como se estivéssemos diante da metáfora bíblica do Gênesis, em que o Espírito das Trevas (Satanás), invejoso da felicidade humana no Paraíso, traveste-se de serpente e oferece o fruto proibido a Eva. Aqui é o próprio fruto proibido que adquire vida própria, aproximando-se da vítima de maneira sutil, rastejante... A droga se transforma, ao mesmo tempo, em agente e objeto da sedução. Teriam Adão e Eva fugido ao convite da serpente, caso tivessem clareza ou estivessem atentos às conseqüências terríveis (a expulsão do Paraíso) da apropriação indevida daquele fruto? Seu comportamento impulsivo cegouos para essas conseqüências e tiveram de amargar a perda do Paraíso, isto é, de uma vida sem sofrimentos. A metáfora parece prestar-se a este neste caso: o dependente químico parece ser seduzido pela busca frenética do prazer a curto prazo, esquecendose ou obscurecendo o impacto posterior dos efeitos colaterais do abuso da droga.

Uma segunda metáfora - caminhar numa trilha cercada de precipícios - também aponta para a necessidade da atenção constante/ clareza no entendimento, no processo de recuperação, tal como o fora assinalado através da metáfora da droga agente/objeto de sedução. O caminhar próximo a despenha-deiros requer cuidados redobrados! Qualquer descuido pode conduzir o viajante para o fundo do precipício. Interessante o paralelo com a metáfora do "fundo do poço", ou seja, aquela condição de desamparo, depressão, sofrimento psíquico 
em que está mergulhado o dependente químico, após um uso prolongado e exagerado da droga. Esta situação, comumente descrita por muitos dos participantes em reuniões de Alcoólicos Anônimos, também foi experimen-tada por estes entrevistados, principalmente antes de iniciar o processo de recuperação neste grupo de ajuda mútua.

\section{3) Participante C}

Este entrevistado destaca o absurdo (paradoxo) da dependência química: de um lado, o dependente químico desejoso de evitar a sua destruição e, de outro, os empecilhos para abandonar a causa de sua própria destruição, o abuso de droga. Para ele, a resolução desse impasse está na compreensão da dependência química como doença crônica. Predomina, pois, em seu discurso, uma concepção de dependência química como doença progressiva, incurável e fatal, que pode apenas ser estabilizada através do evitar o primeiro gole: “(...) crônica e que está estabilizada (...)”, daí a metáfora usada por ele, da ninhada de gatos e a perda do controle após "o primeiro gole": "(...) tem uma ninhada de gatos" aqui dentro do saco, a coisa mais linda. Agora vai ali e dá um pontapé pra tu ver o que acontece. Vai ter gato até na parede trepando "(...). "Evite o primeiro gole pois, se voltar a usar (...)" embala tudo outra vez. Por outro lado, trata-se de uma doença que afeta a mente (o cérebro?) do portador, como fica evidente através do seu uso da metáfora do velho com um pedaço de lajota massacrando o dedo e o dependente químico massacrando o cérebro “(...). E eu fazia isso com o meu cérebro, todo dia, e eu sabia, e muitas vezes eu sabia que droga mata e eu usava justamente por isso, cara." A compulsão para o uso indevido da droga, considerada aqui como uma verdadeira escravidão, é exemplificada através da busca incessante de papelotes de droga "perdidos" na rua e o uso do expediente para justificar-se socialmente, de que estava colecionando figurinha de chicletes quando alguém o recriminava por esse comportamento.

Esta compreensão da dependência química como doença crônica fica mais uma vez enfatizada quando o entrevistado estabelece uma distinção entre recaída e "descompensada", relacionando-as com a duração da perda do auto controle sobre o uso da droga: maior na recaída do que na "descompensada", ou seja, nesta última, o dependente químico está em condições de retornar mais rapidamente à situação de controle. O entrevistado usa a metáfora do alinhamento do carro e do uso de freios, que ilustra muito bem a noção de perda do controle, para descrever a diferença entre recaída e "descompensada": "(...) se tu descompensou, tu tem a possibilidade de retomar, alinhar novamente, centrar de novo, rápido (...) (na recaída) tu não consegue puxar os freios mais (...)" "(...) se tu descompensou, tu tem a possibilidade de retomar, alinhar novamente, centrar de novo rápido (...) se tu recai tu vai te destruindo infinitamente até que alguém vai te persuadir de novo ou que ...". Esta metáfora do dependente químico que precisa aprender a "usar o freio", isto é, autocontrolar-se, é usada também em outra passagem: “(...)... o meu problema não é usar droga é não saber parar de usar droga. E uma vez desencadeado esse processo eu parei dessa forma aí como está descrito puxando os freios e cruzando medicamento (...)".

Destaque-se, também, o emprego da metáfora do assédio da doença, quando o entrevistado tece considerações sobre imprevisto como situação de risco de recaída ou "descompensada". É produzido pela sutileza do assédio da doença da qual o dependente químico é portador. O assédio ocorre justamente no momento de maior vulnerabilidade do dependente. Parece que o entrevistado está personificando ou animizando a doença, atribuindo-lhe poderes de instigação (assédio) : “(...). Eu posso te dizer que é aquilo que tu tá mais vulnerável, 
que tu não tá prevendo e, por isso mesmo, tu não tá preparado pra enfrentar aquela situação. É imprevisto que... (...) E imprevisto é justamente isso ai a sutileza do assédio (...)". A metáfora da "sutileza da droga" destaca, pois, que a recaída não ocorre abruptamente; há um processo lento, às vezes até inconsciente (imperceptível?) de assédio (sedução?): "(...) Inconscientemente tu manipula uma situação pra justificar e daqui a pouco... Ela não vem assim, ela não aparece no punho de um cara que aparece com o punho cerrado e abre com droga. Não é assim que vai acontecer como já aconteceu. Tem toda uma sutileza, tem toda uma história de ir lá, sabe? Fazer um passeio e quando tu menos espera, tu tá numa zona de risco, uma situação comprometedora, né? Quando tu menos espera, tu tá no local apropriado, com droga e com companheira; aí é muito difícil."

Se uma das distinções entre recaída e descompensada é feita em relação à dimensão do controle temporal sobre o processo de uso indevido de drogas, uma segunda distinção faz referência ao grau de consciência envolvido no processo: a recaída parece incluir um componente consciente, intencional (daí o uso da expressão "comportamento comprometido" no caso da recaída), ou seja, a recaída envolve, na maior parte, uma busca intencional, existindo uma preparação psicológica para o ato em si, enquanto que a "descompensada" seria um "acidente de percurso", isto é, muito mais fruto da desatenção do indivíduo. Há uma consciência antecipada da recaída: a situação é planejada (e.g., estar com dinheiro suficiente para a droga, conhecer o local do tráfico, ter história como traficante). Admite, porém, que em alguns casos essa "preparação" se dá até inconscientemente.

A noção de dependência química como doença tem implicações também para a questão da responsabilidade moral do dependente químico: a dificuldade de responsabilizar moralmente o dependente químico por seus atos cometidos sob influência da droga: "(...) E se a gente tá falando que é uma doença como é que tu vai criticar isso, se tu tava fora da realidade tu não tava nem consciente, tu não sabe o que tu tá fazendo ou pelo menos parte disso, né. E tem situações que a gente sabe que tem um apagamento total (...)".

Quanto ao processo de recuperação do dependente químico, este passa necessariamente pelo resgate da auto-estima (a dignidade do ser humano) e, para isso, três condições parecem imprescindíveis: a) identificação com os membros do grupo de auto-ajuda; b) aceitação do toque físico, sem constrangimento; c) comunicação compreensível entre os membros: "(...) Simplesmente a gente ehhh! tava numa loucura meio homogênea e aí houve a possibilidade de uma identificação (...). E foi assim, através de uma sensibilização, de uma identidade, né. Me identificando com as pessoas que já se encontravam ali. (...) Aí eu permiti que alguém me tocasse dado a esse voto de confiança. Não me senti coagido, não me senti eh, como é que eu vou dizer? Assim ... menosprezado nem ridicularizado como em outras circunstâncias eu já me senti. Ah esse daí entendesse, coisa pejorativas. Aqui eu me senti bem à vontade (...) a maneira como foi passado, começou a ser passada as informações fáceis de compreender (...)". Uma metáfora foi usada para destacar esse processo de afiliação: a metáfora da absorção do membro pelo grupo: "(...) eles (o grupo de ajuda mútua) simplesmente me absorveram (...)".

O processo de recuperação é entendido, ainda, como um processo de "purificação", de substituição do homem velho pelo homem novo (para usar uma linguagem bíblica), de retirá-lo da "sarjeta", como fica subentendido através do uso da metáfora do grupo de ajuda mútua como um santuário: "(...) eu digo pra ti que é um santuário porque as pessoas me ergueram, me colocaram em pé e eu permaneci (...)" É um processo de resgate da dignidade 
humana, pelo respeito ao dependente químico, não importando a condição em que este chega ao grupo: "(...) O grupo de ajuda mútua me devolveu a dignidade (...) Ele me resgatou (...)". A idéia de resgate da dignidade humana também está presente através do uso de outra metáfora, tal como a de "tábua da salvação" para o náufrago: "(...) O grupo de ajuda mútua foi a minha tábua de salvação (...) ". Por outro lado, a idéia de resgate da dignidade humana associa-se à idéia do resgate da liberdade humana: "Eu ganhei a possibilidade de escolha, ou seja, resgatei a minha liberdade". Finalmente, a liberdade e dignidade humanas alcançadas durante este processo de recuperação longo e penoso permitem-lhe concluir por sua recusa em retornar à condição anterior: "(...) onde eu estive, eu nunca mais volto (...)".

\section{4) Participante $D$}

Para este entrevistado, a dependência química é vista como doença orgânica (física) que se caracteriza pelo uso desregrado de determinada(s) substância(s) produzindo alteração neuronal e que, por sua vez, é manifestação (sintoma) de outra doença: “(...) a dependência é uma doença, mas eu entendo que essa dependência se instalou pelo uso contínuo da droga, mas o que fez esse uso anormal da substância é uma outra doença. Então, na verdade, aquele uso desregrado da substância é um sintoma, uma manifestação de uma outra doença (...). Então a dependência é uma doença que tem origem em outra, falar em doença é meio complicado, mas que a dependência é doença, é!(...)" "(...) A dependência é doença porque: o que é a dependência? É uma alteração química, a nível neuronal, se está alterado, está doente (...)".

Esta maneira de compreender a dependência química tem implicações para o tratamento e o processo de recuperação pois, de acordo com esta maneira de entender a dependência química, subjacente ao comportamento de consumir a droga existe um distúrbio interno e é este que precisa ser tratado: “(...) então o problema não é usar a droga e sim o que me faz usar a droga. Usar a droga é uma expressão, é como se eu tivesse uma pneumonia e estou tossindo - a tosse é a expressão da pneumonia. O uso da maconha no caso foi a expressão de um transtorno, distúrbio, de algo que não é normal, de uma anormalidade." Isto fica evidente na medida em que, mesmo depois de interromper durante muito tempo o uso da droga, o dependente pode continuar sentindo-se profundamente infeliz. Daí, o objetivo de um programa de tratamento não deve restringir-se à ruptura do seu vínculo com a droga, é preciso tratar do distúrbio que leva ao uso indevido da droga: “(...) recuperações que não valeram a pena, pessoas que pararam de usar o álcool, principalmente, estão sem o uso da substância mas são pessoas que apresentam um grau de sofrimento emocional muito grande, são pessoas sem ação social nenhuma, inertes, cheios de problemas, traumas, medos. E a vida não muda nada, na verdade eu acho que fica pior, porque a vida se torna um martírio. Essas são recuperações que não valeram a pena, não se recuperou nada, você retirou a substância e deixou o doente, (...)".

Além de suas implicações para o tratamento, esta concepção de dependência química como doença apresentaria, na opinião deste entrevistado, uma implicação prática, relacionada com a vantagem de maior facilidade de compreensão por parte do dependente, a respeito de sua condição. Em outras palavras, a compreensão de que é portador de uma doença poderia sensibilizá-lo a buscar ajuda, através de um tratamento: "(...) é uma doença entre aspas; na verdade, é um transtorno, um distúrbio. É que é mais fácil falar em doença, é mais direto, assusta mais logo, né?!"

A fim de exemplificar sua noção de uma doença (a dependência química) que está relacionada com outra doença, da qual a 
primeira é apenas um sintoma, este entrevistado toma a si próprio como modelo, identificando sua neurose ou sua depressão como fatores associados à sua dependência química: "(...)Tudo tem me levado a crer que eu sou depressivo (...) acabava bebendo para esquecer, para ficar tranqüilo, para melhorar, porque o estado emocional fica muito ruim durante uma crise depressiva (...) uma visão bem atual, muito organicista, né?(...) assim eu tô num processo depressivo que eu acabava, por este processo, mudando meus valores, meus conceitos e acabava usando a substância na busca de uma melhora (...)Porque a dependência uma vez instalada nunca mais desinstala (...) começam uma série de transtornos, de achar que não tá certo, com raiva de outros, achar que os outros estão me perseguindo e isso começa a provocar distúrbios no engajamento social, conflitos, desajustes, esses são sintomas que antecedem o uso (...) Na verdade são esses sintomas que eu tô tendo numa crise, no meu caso eu acredito que é depressão." Hoje, este participante consegue manter sob controle o uso indevido de drogas, ou seja, em seu processo de recuperação está conseguindo romper o elo entre sua doença (a neurose, a depressão) e o abuso de droga. Por outro lado, esse distúrbio básico continua latente, passando a expressá-lo através de outros sintomas: "(...) só que eu tenho conseguido até agora evitar o processo de uso da droga, eu descarrego minhas neuroses de outra maneira (...) São quase sete anos de abstinência onde eu tenho recaídas dentro da doença sem reinstalar a dependência" .

\section{DISCUSSÃo}

Da análise comparativa das quatro sínteses acima apresentadas, sobressaemse as seguintes metáforas: 1) o processo de recaída é considerado como a condição em que o dependente químico pode retornar à condição de degradação humana, trans- formando-se num "lixo humano", "lançando-se na lama" ou, ainda, desvestindo-se da condição humana ao se tornar um "vegetal"; 2) o processo de recaída também é semelhante ao processo de dirigir um automóvel, seja quando o condutor não consegue mais realinhar o veículo quando, por exemplo, este se desvia para o acostamento; seja quando o freio começa a falhar; enfatiza-se a noção da perda de controle após o "primeiro gole"; 3) a dificuldade e a complexidade do processo de recuperação são comparadas com o caminhar numa trilha à beira de precipícios, em que qualquer descuido pode propiciar um retorno à condição de degradação anterior; 4) a dependência química é comparada a uma ninhada de gatos que está presa num saco: se esta encontrar uma fresta, põe-se em debandada; desta forma, enfatiza-se a noção de perda de controle por ocasião do "primeiro gole"; 5) a dependência química e a própria droga são vistas como o agente/objeto instigador que conduz à recaída; algo similar ao processo de sedução/tentação sutil, descrito no livro do Gênesis, em que o primeiro casal é seduzido pela serpente; destaca-se a natureza de doença crônica e a atenção que se deve ter diante das situações de risco e dos imprevistos; 6) o grupo de ajuda mútua é considerado como um santuário, pela capacidade que possui de restituir a dignidade e liberdade humana, resgatando o dependente químico do "fundo do poço" ou da "sarjeta"; enfatiza-se, pois, a função humanizadora e libertadora do grupo de ajuda mútua; enfim, uma função de purificação e libertação do jugo exercido pela droga sobre o indivíduo; 7) o grupo de ajuda mútua é visto como "a tábua de salvação" ao permitir retornar à vida aquele que se achava condenado à morte pela droga.

Como se pode observar, a análise do discurso dos quatro participantes revela com bastante clareza e de forma explícita uma compreensão sobre a dependência química e o processo de recaída, o qual se mostrou perfeitamente compatível com o modelo de doença que circula entre os participantes desse 
grupo de ajuda mútua, como verificamos anteriormente (Pick e Baus, 1996), bem como é comum encontrar no discurso de membros dos Alcoólicos Anônimos ou na literatura respectiva (Alcoholics Anonymous, 1977). Trata-se de uma concepção de doença crônica, segundo a qual, através do processo de recuperação, consegue-se apenas estabilizála, ou seja, ao "primeiro gole" pode-se novamente despertar o "demônio" que estava silenciado momentaneamente. A análise das metáforas permitiu verificar sua adequação ao modelo de dependência química como doença crônica: isto ficou nítido nas diversas instâncias desta análise, seja aquelas relacionadas com o processo de recaída, aquelas relativas ao processo de recuperação ou ao grupo de ajuda do qual fazem parte esses integrantes, seja, ainda, aquelas diretamente relativas à dependência química ou às drogas, em geral.

Este estudo permite concluir com Moser (2000) a respeito da relevância da análise da metáfora como instrumento valioso na pesquisa psicológica. Entendemos que este tipo de análise permite compreender a forma como dependentes químicos se vêem, como eles relacionam os efeitos da droga com as perturbações psicológicas vivenciadas e podem esclarecer a respeito da gravidade do quadro de dependência química dos pacientes.

\section{REFERÊNCIAS}

ALCOHOLICS ANONYMOUS. (1977). Viver Sóbrio. São Paulo: Centro de Distribuição de Literatura de Alcoólicos Anônimos para o Brasil.

MOSER, K. S. (2000, June). Metaphor Analysis in Psychology - Method, Theory, and Fields of Application [22 paragraphs]. Forum Qualitative Sozialforschung / Forum: Qualitative Social Research [On-line Journal], 192). Available at: http://qualitativeresearch.net/fqs/fqs-e/2-00inhalt-e.htm

PICK, R. E. \& BAUS, J. (1996). Análise de conteúdo de verbalizações de dois participantes de grupo de ajuda mútua de dependentes químicos relativas aos processos de dependência química e de recuperação. [Resumos] In: Anais da IV Semana da Pesquisa da UFSC, (p. 262). Florianópolis, SC: Imprensa Universitária.

VOSNIADOU, S. \& ORTONY, A (eds) (1989). Similarity and analogical reasoning. New York: Cambridge University Press. 
